Research Article

\title{
Experimental Study of Vapor Supercavitation Suppression of Capillary Outlet Jet Noise
}

\author{
Qianxu Wang $\mathbb{D}^{\mathbb{D}}$, Yicai Liu $(\mathbb{D}$, Yao Yao, and Yu Zhang \\ School of Energy Science and Engineering, Central South University, Changsha 410083, China \\ Correspondence should be addressed to Yicai Liu; lyccsu@csu.edu.cn
}

Received 4 March 2021; Revised 19 April 2021; Accepted 30 April 2021; Published 8 May 2021

Academic Editor: Jia-Bao Liu

Copyright ( 2021 Qianxu Wang et al. This is an open access article distributed under the Creative Commons Attribution License, which permits unrestricted use, distribution, and reproduction in any medium, provided the original work is properly cited.

\begin{abstract}
The degree of bubble bursting at the inlet of an evaporator is the key factor to determine the size of the injection noise at the capillary outlet. In this study, by using the theory of cavitation dynamics, the transition tube between the capillary and evaporator is improved to suppress the bubble bursting at the entrance of the evaporator, so as to reduce the jet noise at the outlet of the capillary. The influence of aeration structure on noise reduction of a refrigerator (Haier BCD-520) was studied by numerical simulation, and experiments were carried out. The results show that the admixture structure significantly inhibits the bubble bursting and reduces the injection noise by $1.5 \mathrm{~dB}(\mathrm{~A})$.
\end{abstract}

\section{Introduction}

Noise is one of the most important quality indicators of refrigerators. To solve this problem, pioneers invest a lot of budget and manpower [1-7]. With the continuous improvement and optimization of the refrigerator compressor, the compressor noise has been greatly reduced. However, the refrigerant flow noise became easier to be heard, especially the jet noise at the capillary outlet. Jet noise affects not only people's quality of life but also the hygiene of food in refrigerators [8]. Since the hydrodynamic characteristics of two-phase flow change with the change of bubble characteristics, bubbles are considered to be one of the main sources of noise of two-phase flow. In recent years, many scholars began to conduct scientific experimental research on noise characteristics and also proposed noise suppression methods. For example, Jascha Ruebeling and Steffen Grohmann analyzed the mechanism of fluid-induced noise at the capillary outlet of the refrigeration system [9]. Min Seong Kim et al. proposed using the noise model diagram to predict the noise caused by refrigerants in refrigerators [10]. Hyung Suk Han et al. studied the refrigerant flow pattern and bubble characteristics at the inlet of the evaporator and discussed the relationship between refrigerant noise and bubble characteristics [11-13]. Yubo Xia et al. established a transition tube with different structures between the capillary and the evaporator and experimentally studied the influence of refrigerant flow state in the transition tube on the refrigerator noise [14]. When the refrigerant is in twophase flow state, it usually produces refrigerant flow noise. At present, the effect of the proposed scheme to suppress the jet noise from the capillary outlet of refrigerator is not very ideal. The study based on the theoretical and experimental research, the refrigerant in the outlet of capillary jet noise, considering the pipe fluid dynamics and bubble dynamics, aimed at curbing the evaporator inlet air bubbles burst and thus effectively controls the refrigerant in capillary outlet jet noise, puts forward the feasible solution, and achieves the goal of curing.

\section{Frequency Distribution of Refrigerator Noise}

Refrigerator noise is mainly the audible sound between $20 \mathrm{~Hz}$ and $20 \mathrm{kHz}$ that humans can hear. The system noise is mainly distributed between $20 \mathrm{~Hz}$ and $10 \mathrm{kHz}$, including the following:

(1) Mechanical noise $(0 \mathrm{~Hz}-300 \mathrm{~Hz})$

(2) Bubble bursting noise $(300 \mathrm{~Hz}-2500 \mathrm{~Hz})$

(3) Electromagnetic noise (above $2500 \mathrm{~Hz}$ ) 
(4) Cross noise of three kinds of noise (resonance)

The typical spectrum distribution is shown in Figure 1. Figure 1 shows that the refrigerator noise varied with direction. The noise at the side of the compressor chamber and at the left side was slightly louder than the noise at the front and right sides. A peak was observed with the range of $125 \mathrm{~Hz}-2000 \mathrm{~Hz}$.

Since the size and shape of the bubble vary with the flow pattern in the pipeline, the acoustical characteristic should be varied according to the flow pattern in the pipeline. The acoustical characteristic can be estimated according to equation (1) [15], by assuming that a unit bubble can be modeled as a one-degree of freedom springmass system.

$$
m_{b} v_{1}+b v_{2}+k\left(v-V_{0}\right)=P_{A} e^{j \omega t},
$$

where

$$
\begin{gathered}
m_{b}=\frac{\rho}{4 \pi R_{0}}, \\
k=\frac{\gamma p}{V_{0}} .
\end{gathered}
$$

We assumed that the volume of the bubble oscillates with an amplitude of $\alpha$ as follows:

$$
v=V_{0}+\alpha \sin \frac{2 \pi t}{T} .
$$

Then, the natural frequency of the oscillating bubble can be obtained as follows [16]:

$$
f_{n}=\frac{1}{2 \pi R_{0}} \sqrt{\frac{3 k P}{\rho}},
$$

where $R_{0}$ is the equivalent bubble radius.

Since the burst frequency of bubbles is close to the natural frequency of bubbles, it can be concluded that the frequency of bubble burst noise is mainly distributed between $125 \mathrm{~Hz}$ and $2000 \mathrm{~Hz}$.

When the equivalent bubble radius is larger than the inner tube radius, the bubble shape cannot be spherical. Since the bubble radius is larger than the pipe radius, it should be irregularly deformed along the axial direction of the pipe and become slug flow. In this paper, the shape of long projectile was assumed to be cylindrical for the convenience of explaining its frequency characteristics [17].

\section{Numerical Simulation of Jet Noise at the Capillary Outlet}

For small refrigeration systems, the capillary has been widely used because the capillary has numerous advantages such as simple structure, low cost, convenient installation, and stable quality. Previous studies showed that a metastable phenomenon occurs in the refrigerant flow through the capillary, which affects the flow rate, pressure, and injection state at the capillary outlet.
According to the reference, the jet noise at the capillary outlet is mainly caused by the refrigerant bubble growing violently and bursting suddenly at the inlet of the evaporator. Usually, there is more than one evaporator in the refrigeration system of the refrigerator. For example, the refrigerator selected in this experiment is divided into the fresh-keeping chamber, the cold chamber, and the freezing chamber. There are three evaporators, which exchange heat with the inside of the refrigerator through natural convection and radiation heat exchange. In this experiment, the structure of the capillary outlet of the fresh-keeping chamber is improved, which directly affects the burst of refrigerant bubbles at the capillary outlet and then affects the injection noise level at the capillary outlet. By comparing the numerical simulation results before and after optimization, the preliminary analysis was carried out.

3.1. Capillary Numerical Simulation. In order to describe the flow of refrigerant in the capillary outlet and the transition tube accurately, the capillary numerical simulation model was firstly established. The capillary numerical simulation was divided into three parts.

3.1.1. Contraction Section of Capillary Inlet. The singlephase refrigerant flows from the drying filter into the capillary. As the pipe size suddenly decreases, the refrigerant flow rate will be increased and the pressure will be decreased. The pressure drop of this part can be expressed as

$$
\Delta p=\zeta \frac{G^{2} v_{0}}{2},
$$

where $\zeta$ is local resistance coefficient of import which is given by

$$
\begin{aligned}
\zeta & =\frac{1}{A_{c}^{2}}\left[\left(\frac{1}{\beta_{c}^{2}}\right)-2\left(\frac{1}{\beta_{c}-1}\right)\right], \\
\beta_{c} & =\frac{1}{0.693 \sqrt{1-\beta}+1},
\end{aligned}
$$

where $A_{c}$ is the cross-sectional area of capillary, $A_{d}$ is the cross-sectional area of filter drier, and

$$
\beta=\frac{A_{c}}{A_{d}} \text {. }
$$

3.1.2. Subcooled Liquid Single-Phase Model. The liquid refrigerant flows at a high speed in the capillary tube, causing strong friction with the inner surface of the capillary tube and then resulting in the decrease of refrigerant pressure. The control equation is as follows.

Momentum equation:

$$
\frac{\mathrm{d} p}{\mathrm{~d} z}=-f_{s p} \frac{G_{c}^{2} v_{l}}{2 D_{c}},
$$

where $f_{s p}$ is the friction drag coefficient and $f_{s p}$, using the Churchill equation, gives 


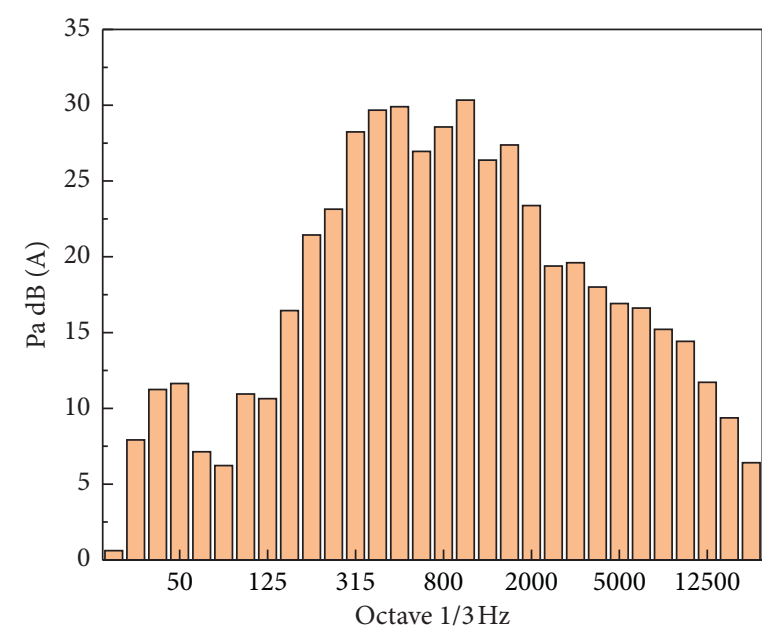

Octave $1 / 3$ front: $S(A)$

(a)

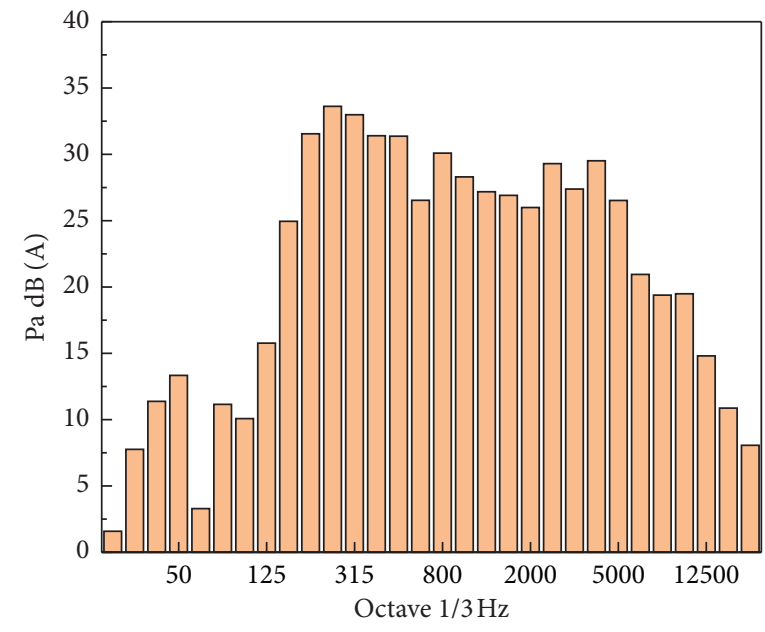

Octave $1 / 3$ rear: $S(A)$

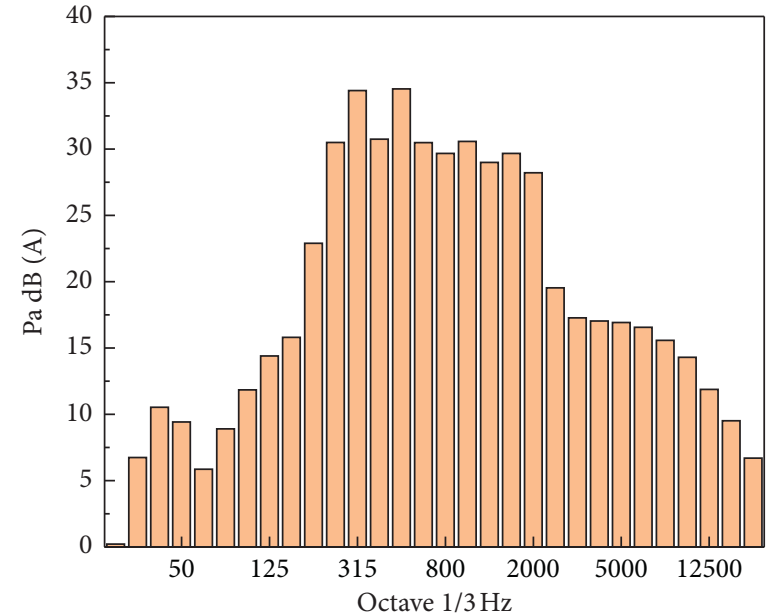

Octave 1/3 left: $S(A)$

(b)

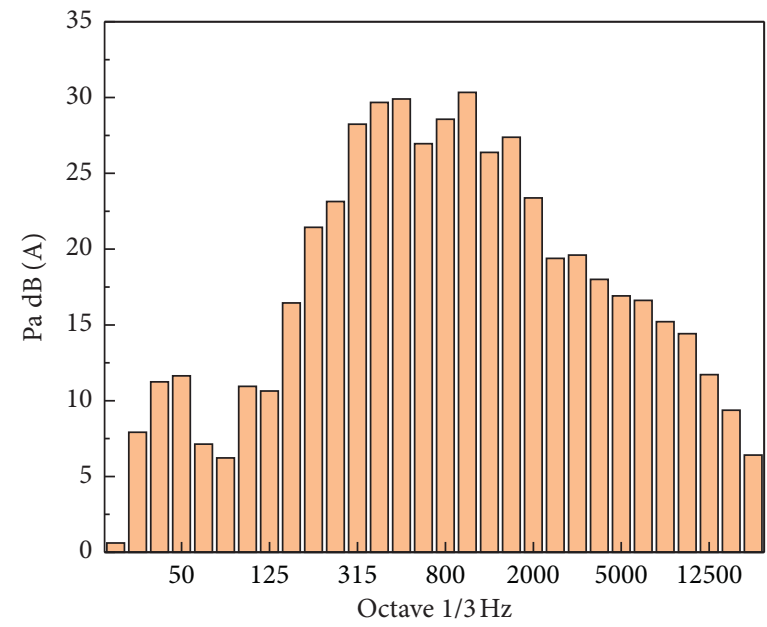

Octave $1 / 3$ right: $S(A)$

(d)

FIgURE 1: Distribution of the noise spectrum of the refrigerator in four directions.

$$
\begin{aligned}
f_{s p} & =8\left[\left(\frac{8}{\mathrm{Re}}\right)^{12}+\frac{1}{(A+B)^{1.5}}\right]^{1 / 12}, \\
A & =\left[2.457 \ln \frac{1}{(7 / \mathrm{Re})^{0.9}+0.27(\varepsilon / D)}\right]^{16}, \\
B & =\left(\frac{37530}{\mathrm{Re}}\right)^{16} .
\end{aligned}
$$

Energy equation in the capillary:

$$
\frac{\mathrm{d} T_{c}}{\mathrm{~d} z}=-\frac{h_{c} \pi D_{c}}{m_{c} c_{p_{c}}}\left(T_{c}-T_{w}\right)
$$

Energy equation in compressor suction pipe:

$$
\frac{\mathrm{d} T_{S}}{\mathrm{~d} z}=-\frac{h_{s} \pi D_{s}}{m_{s} c_{p_{s}}}\left(T_{s}-T_{w}\right)
$$

Ignoring the contact thermal resistance and axial thermal conductivity between the capillary tube and the compressor return tube, the energy equation is

$$
h_{c} \pi D_{C}\left(T_{C}-T_{W}\right)=h_{s} \pi D_{S}\left(T_{W}-T_{S}\right) .
$$

The convective heat transfer coefficient of capillary and compressor return pipe is given by Pata [18]:

$$
\begin{aligned}
& \mathrm{Nu}_{c}=0.023 \operatorname{Re}^{0.8} \operatorname{Pr}^{0.3}, \\
& \mathrm{Nu}_{s}=0.0395 \operatorname{Re}^{0.8} \operatorname{Pr}^{0.333} .
\end{aligned}
$$


3.1.3. Gas-Liquid Two-Phase Flow Model. As the refrigerant flows in the capillary, the refrigerant pressure begins to drop to the saturation pressure corresponding to the supercooled temperature, and the refrigerant is in a two-phase flow state. The control equation is as follows.

Mass conservation equation:

$$
\frac{\mathrm{d}(\rho V)}{\mathrm{d} z}=0
$$

Momentum equation:

$$
-\frac{\mathrm{d} p}{\mathrm{~d} z}=\frac{4 \tau_{w}}{D_{C}}+G^{2} \frac{\mathrm{d}}{\mathrm{d} z}\left[x v_{g}+(1-x) v_{1}\right],
$$

where shear stress is given as follows:

$$
\tau_{w}=f \frac{G^{2} v}{8} .
$$

3.2. Vapor-Liquid Two-Phase Numerical Simulation of the Transition Tube. According to the state parameters of refrigerant R600a at the capillary outlet, the gas-liquid two-phase flow model and the Schnerr-Sauer cavitation model of the transition tube were established by using CFD commercial software. Unstructured mesh was used to build a 3D model. The boundary conditions are velocity inlet and pressure outlet. The reliable turbulence model and the mixture model were used for the two-phase flow model.

The cavitation model was selected. The capillary inner diameter is $D 1=0.7 \mathrm{~mm}$, and the outer diameter is $D 2=1.8 \mathrm{~mm}$. The length of the transition tube is $70 \mathrm{~mm}$. The inner diameter of the transition tube is $D 3=6 \mathrm{~mm}$, and the outer diameter is $D 4=8 \mathrm{~mm}$. The capillary was inserted into the transition tube at a depth of $19.65 \mathrm{~mm}$. The inner and outer diameters of bypass tubes are the same as those of capillary tubes. The insertion position of the bypass pipe is $20 \mathrm{~mm}$ away from both ends of the transition pipe. The structure before and after improvement is shown in Figures 2 and 3.

The design conditions of Haier BCD-520 were selected for simulation, and the calculated parameters are shown in Table 1.

The simulation results are shown in Figure 4.

The local pressure and gas-phase volume fraction at the axis of the transition pipe are shown in Figure 4 . The starting point of the horizontal coordinate in Figure 4 represents the position of the end of the capillary outlet, and the positive direction of the abscissa is consistent with the refrigerant flow direction. Figure 4(a) represents the partial pressure distribution of the refrigerant in the transition pipe, which shows that the vapor admixture structure can obviously increase local pressure of the evaporator inlet by introducing the gas-phase refrigerant. Figure 4(b) represents the volume fraction distribution of the gas-phase refrigerant in the transition pipe, which shows that the gas-phase volume fraction of the refrigerant at the transition pipe is significantly decreased after optimization because the refrigerant cavitation phenomenon is suppressed, the supercavitation state is reached, and at the same time, the pressure fluctuation become smaller. According to the results, we can know that the structure can effectively inhibit the bursting of the refrigerant bubble at the entrance of the evaporator, so that the bubbles continue to flow along the pipeline and at the same time it can reduce the noise value of the refrigerant jet at the capillary outlet, solving the noise problem from the source and achieving the effect of treating both symptoms and root causes.

\section{Experimental Study on Jet Noise of Throttle Capillary in the Refrigerator}

4.1. Experimental Equipment. A refrigerator refrigeration system with prefabricated transition tubes is shown in Figure 5. Between the capillary outlet and the evaporator inlet, improved transition structure is installed, while the rest of the system remains in relative position.

4.2. Test Equipment. The experimental testing room and experimental equipment are provided by Qingdao Haier. The experiment was carried out in a standard noise suppression chamber. The refrigerator prototype was Haier BCD-520, and the noise spectrum analyzer was LMS Test.Lab. According to the test method specified in GB_T8059, the refrigerator is placed on the horizontal ground in the middle of the muffling room, and four microphones are placed around the refrigerator. The distance of microphones from the refrigerator is $1 \mathrm{~m}$, and the height is $1.5 \mathrm{~m}$. The refrigerator noise evaluation system is shown in Figure 6. The ambient temperature and humidity are $20.5^{\circ} \mathrm{C} /$ $73 \%$, and the atmospheric pressure is $1.0118 \times 10^{5} \mathrm{~Pa}$. The temperature of the fresh-keeping chamber is set at $6^{\circ} \mathrm{C}$.

4.3. Result Analysis. From the above discussion, it can be found that the burst noise of the bubble at the capillary outlet is one of the main noise sources of the refrigerator, and its main frequency range is $250-8000 \mathrm{~Hz}$. Then, we conducted experiments within this noise frequency range. The experimental data are shown in Figures 7 and 8.

As we can see from Figures 8(a) and 8(b), the improved noise spectrum becomes smoother, especially within $125 \mathrm{~Hz}-2000 \mathrm{~Hz}$. After optimization, the level of noise signal is reduced by $1.5 \mathrm{~dB}(\mathrm{~A})$, and the fluctuation of noise curve is smaller. These results show that the optimization is feasible. That is to say, by adjusting the vapor admixture at the evaporator entrance, the bubble burst at the capillary outlet can be inhibited, as well as the spectrum amplitude of the jet noise at the capillary outlet.

The standard specifies that ambient temperature in the laboratory can be from 10 to $43^{\circ} \mathrm{C}$; in our test, it was $(25 \pm 0.5)^{\circ} \mathrm{C}$. The relative humidity in the laboratory was generally $(55 \pm 1) \%$, and the ambient airflow was less than $0.25 \mathrm{~m} / \mathrm{s}$. 


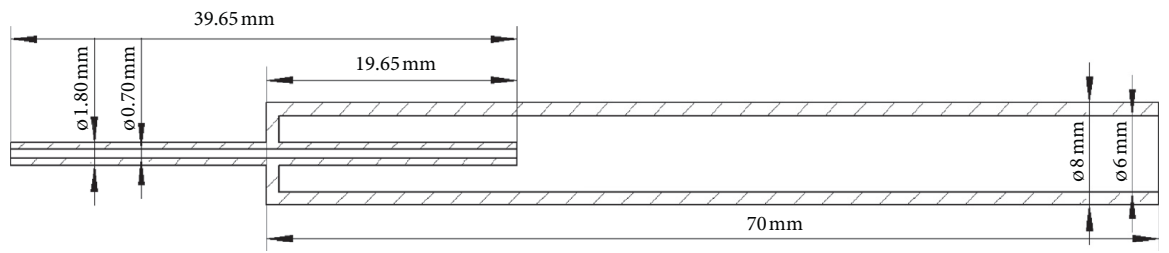

Figure 2: Transition pipe before optimization.

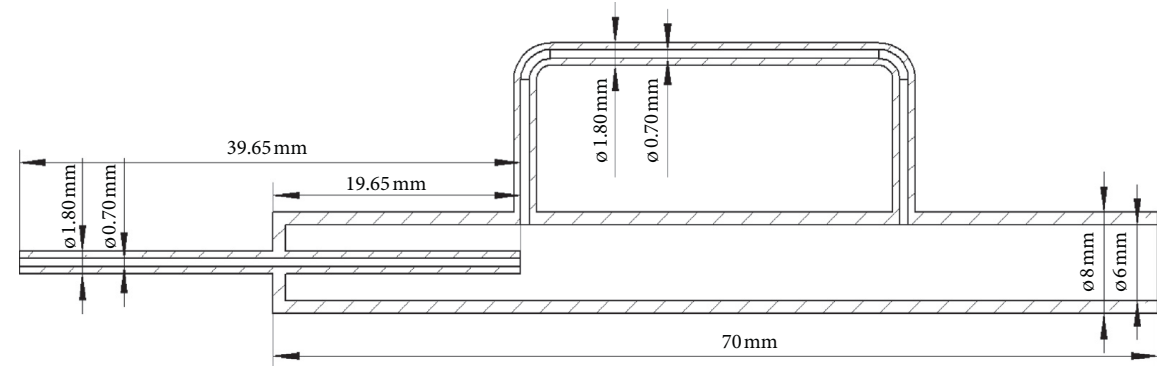

Figure 3: Transition pipe after optimization.

TABLE 1: The calculation parameters of the refrigerator.

\begin{tabular}{lc}
\hline Calculation parameter & Value \\
\hline Capillary inner diameter, Dc/m & 0.0007 \\
Compressor suction pipe inner diameter, Ds/m & 0.006 \\
The length of the capillary before exchanging heat with compressor suction pipe, lin $/ \mathrm{m}$ & 0.45 \\
The length of the capillary exchanging heat with compressor suction pipe, lhx $/ \mathrm{m}$ & 0.8 \\
The total length of the capillary, $1 / \mathrm{m}$ & 3.05 \\
Condensation temperature, $\mathrm{Tcn} /{ }^{\circ} \mathrm{C}$ & 54 \\
Capillary inlet temperature, $\mathrm{Tsc} /{ }^{\circ} \mathrm{C}$ & 30 \\
Evaporation temperature, $\mathrm{Te} /{ }^{\circ} \mathrm{C}$ & 1 \\
Capillary roughness & 0.00000046 \\
Refrigerant & $\mathrm{R} 600 \mathrm{a}$ \\
\hline
\end{tabular}

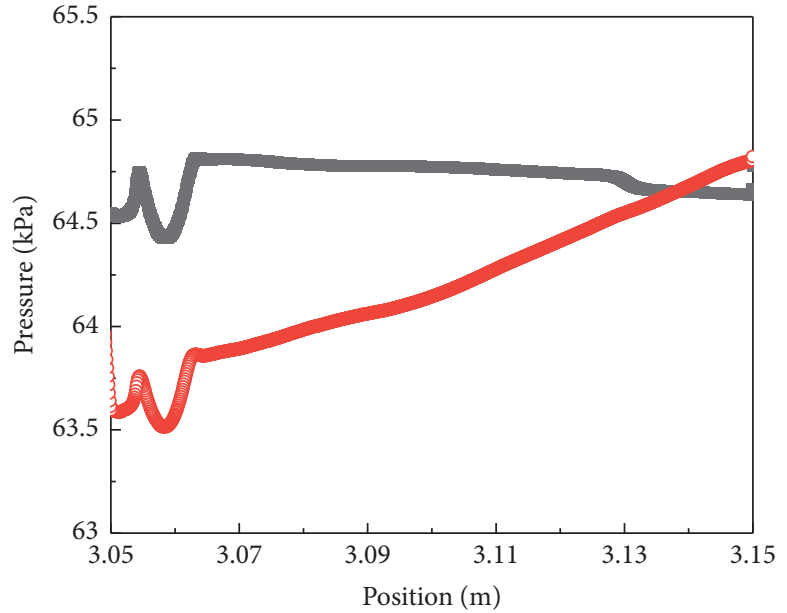

- Optimization

○ Initial

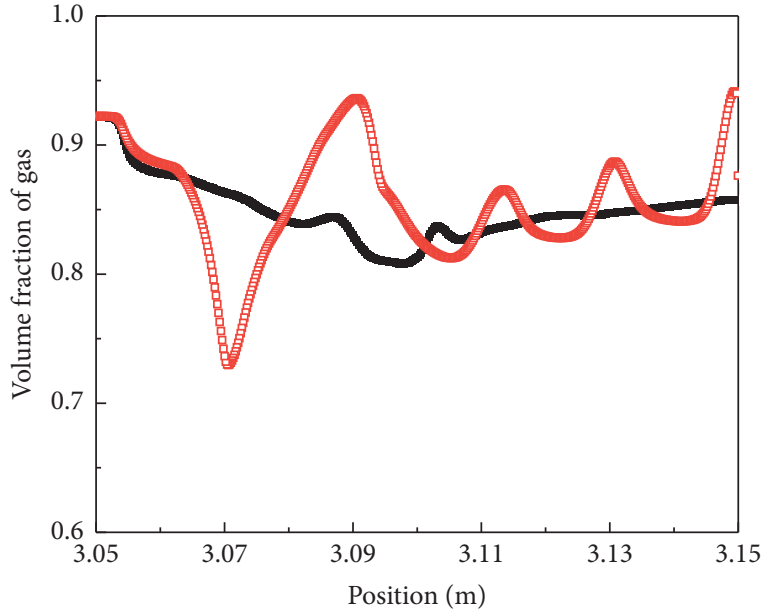

- Optimization

$\square$ Initial

(a)

(b)

Figure 4: Local pressure and liquid-phase volume fraction at the transition pipe. (a) Local pressure at the transition pipe. (b) Gas-phase volume fraction at the transition pipe. 


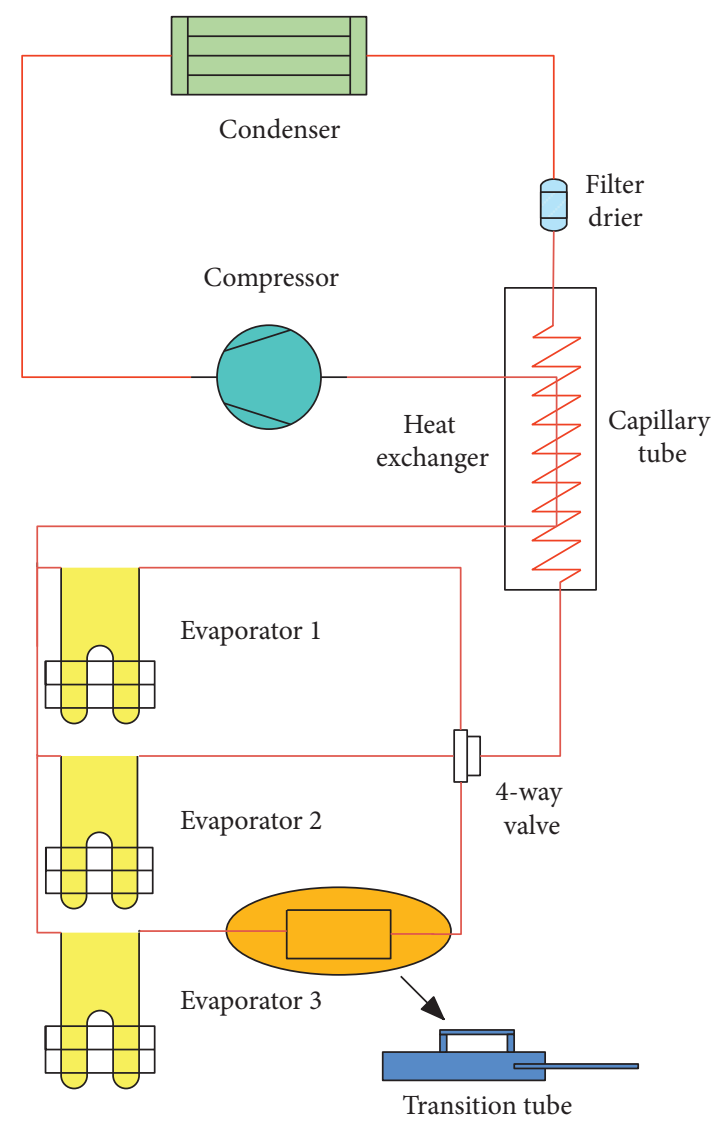

Figure 5: Refrigeration system with a transition pipe.

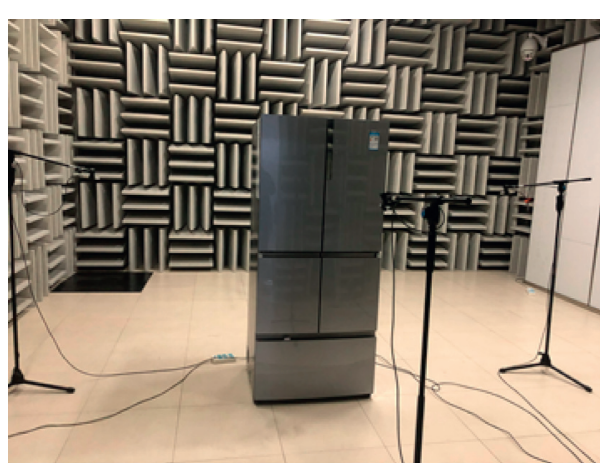

(a)

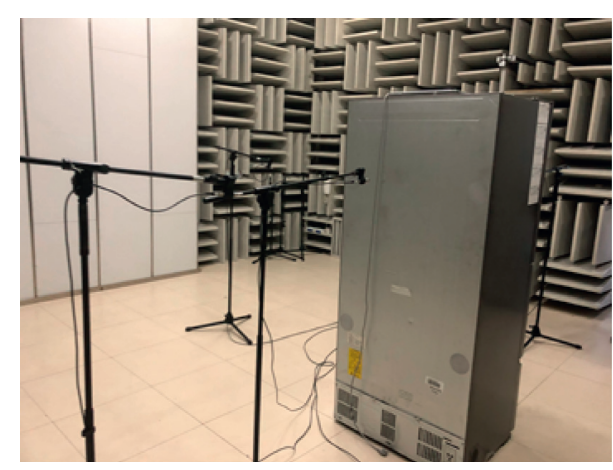

(b)

Figure 6: $(\mathrm{a}, \mathrm{b})$ Layout of the test equipment. 


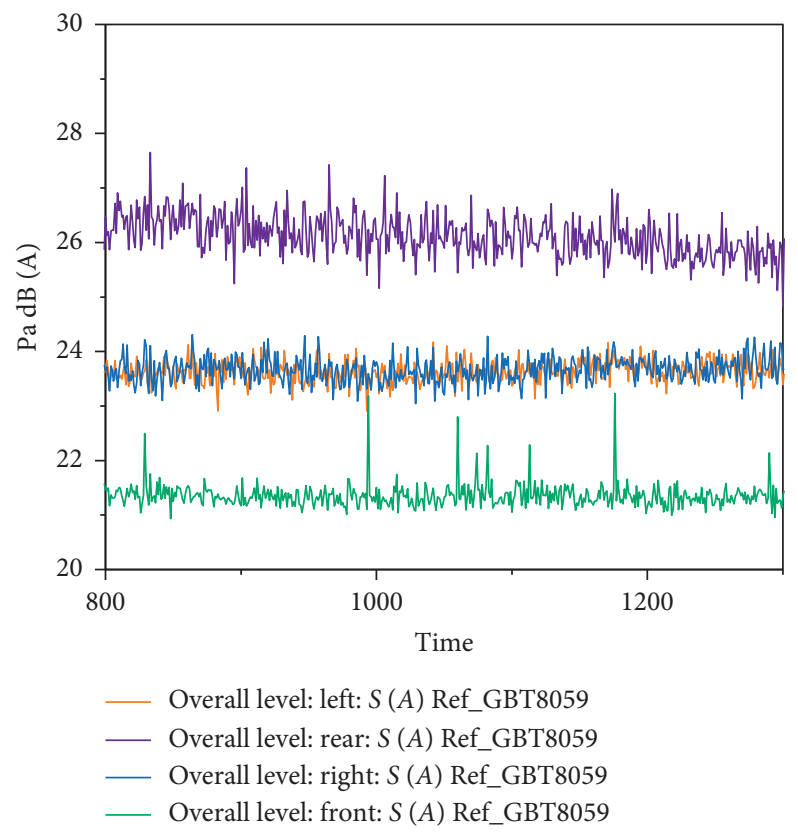

(a)

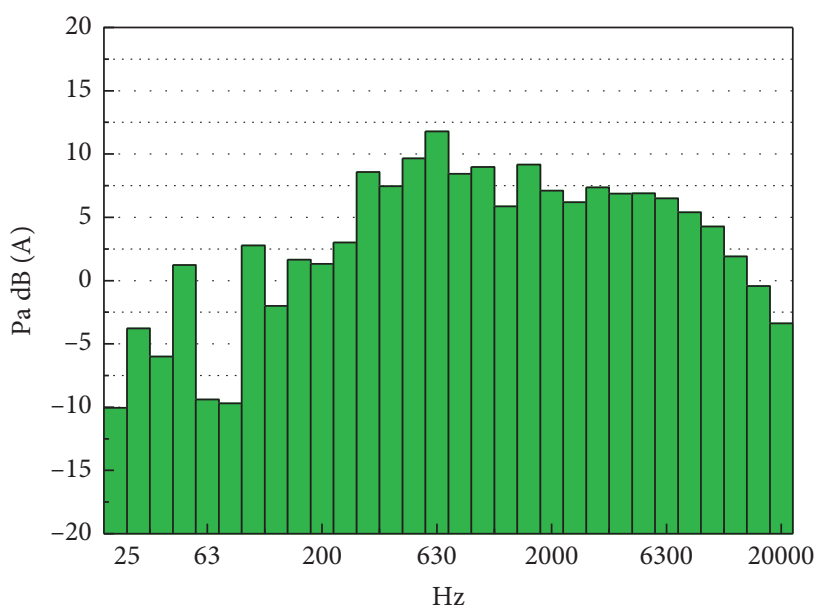

$\square$ Octave $1 / 3$ front: $S(A)$

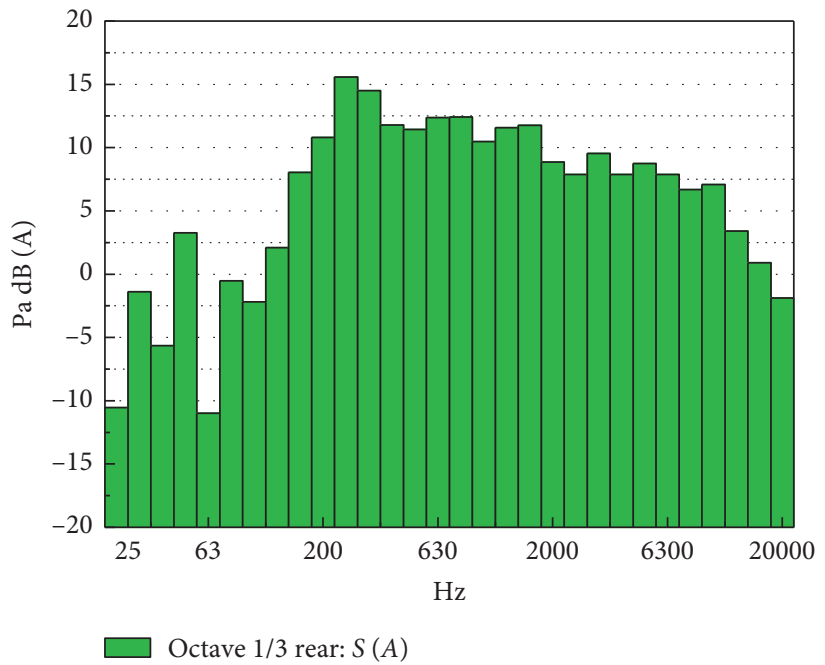

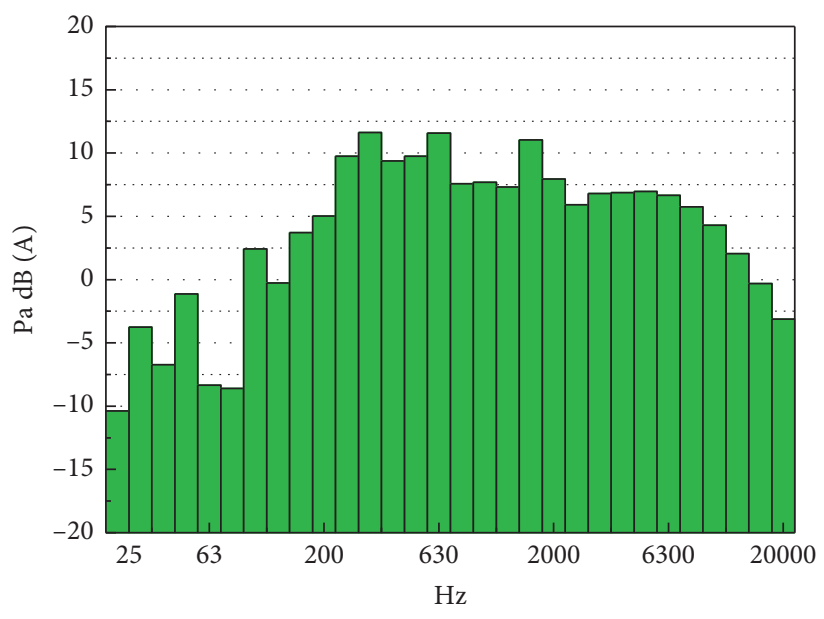

$\square$ Octave 1/3 left: $S(A)$

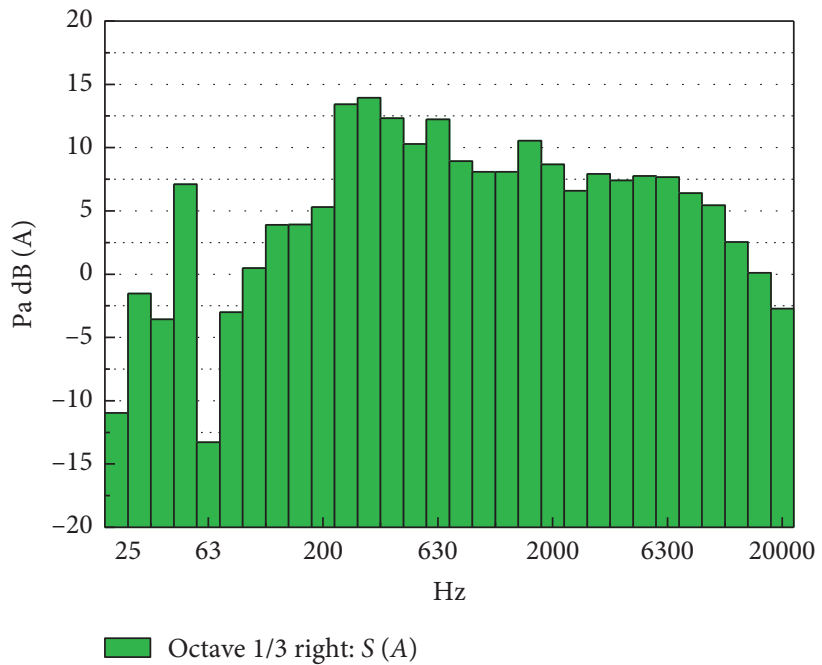

(b)

FIGURE 7: (a) Noise curves of running cycle of the refrigerator before improvement. (b) Noise spectrum distribution of running cycle of the refrigerator after improvement. 


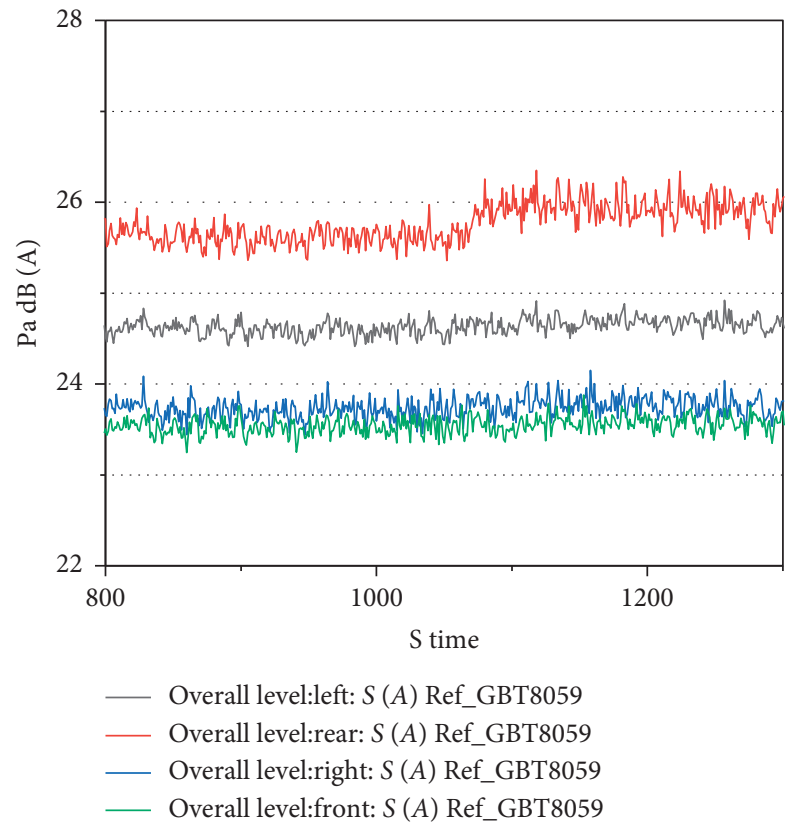

(a)
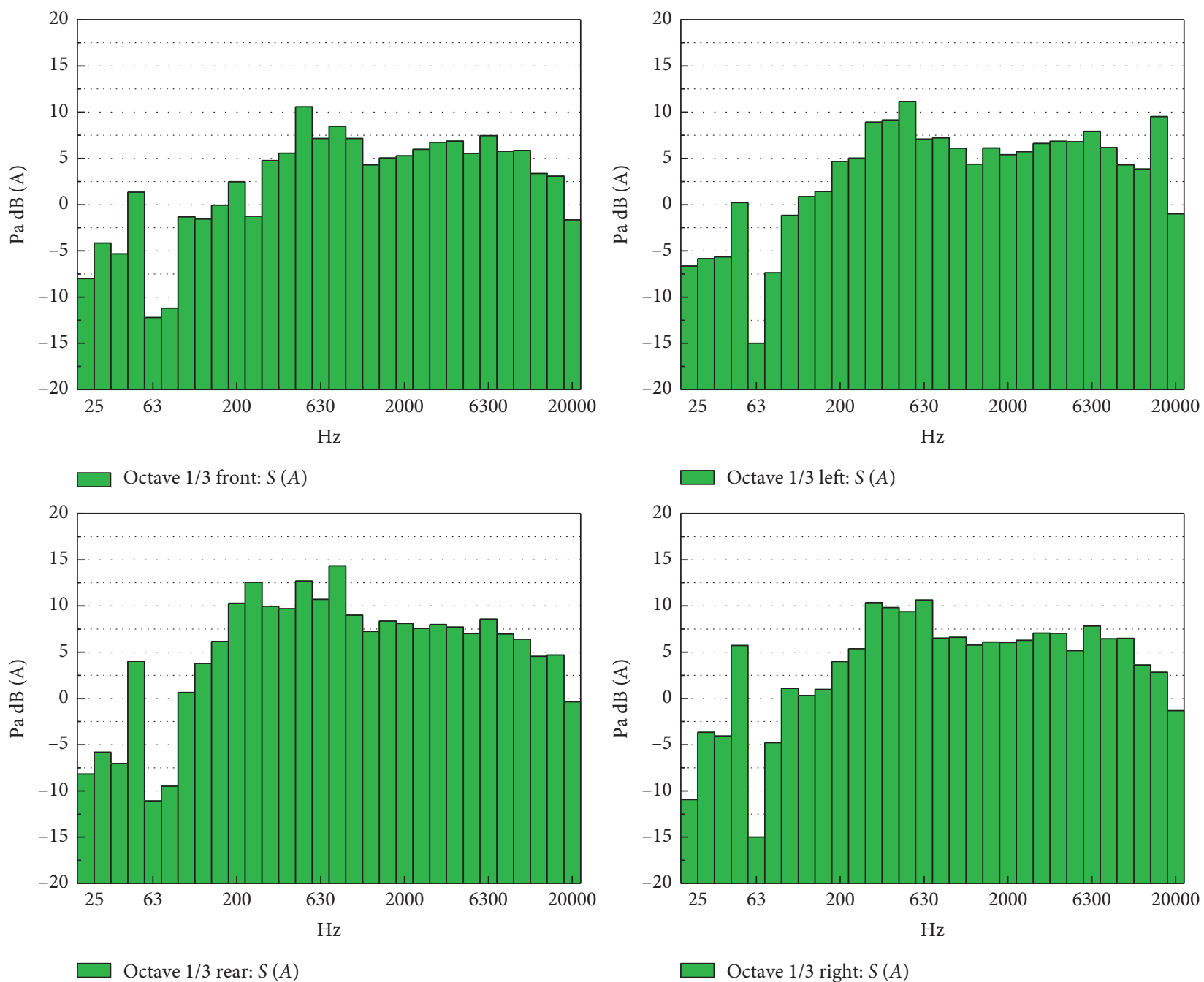

(b)

Figure 8: (a) Noise curves of running cycle of the freezer after improvement. (b) Noise spectrum distribution of running cycle of the refrigerator after improvement. 


\section{Conclusion}

The theoretical and experimental results show that the noise from the capillary outlet directly affects the noise level of the refrigerator. In this study, the bubble burst at the capillary outlet was inhibited, and the jet noise at the capillary outlet was reduced by installing the vapor admixture device at the evaporator inlet of the refrigerator, so as to reduce the overall noise level.

Therefore, in order to reduce the noise level of the refrigerator, the refrigerator manufacturer should choose the compressor with high efficiency and low noise for the refrigerator, improve structure, and study the matching of the various components in the refrigeration system.

\section{Nomenclature}

A: Area, $\mathrm{m}^{2}$

$c_{p}$ : Specific heat at constant pressure, $\mathrm{J} /(\mathrm{kg} \mathrm{K})$

D: Diameter, $\mathrm{m}$

$f$ : Friction coefficient

$f_{n}$ : Natural frequency of oscillating bubble, $\mathrm{Hz}$

G: $\quad$ Mass flux, $\mathrm{kg} / \mathrm{m}^{2} \mathrm{~s}$

$H$ : Convective heat transfer coefficient, $\mathrm{W} / \mathrm{m}^{2} \mathrm{~K}$

$k$ : Equivalent stiffness term of the bubble

$m$ : Mass, $\mathrm{kg}$

Nu: Nusselt number

$P$ : $\quad$ Pressure of the liquid surrounding of the bubble, $\mathrm{Pa}$

$P_{A}$ : Acoustic pressure of the bubble, $\mathrm{Pa}$

Pr: Prandtl number

Re: Reynolds number

$R_{0}$ : Equivalent radius of the bubble assuming its shape is spherical, $\mathrm{m}$

T: $\quad$ Temperature, ${ }^{\circ} \mathrm{C}$

$V$ : Volume of the bubble

$V_{0}$ : Initial volume of the bubble, $\mathrm{m}^{3}$

$x$ : Dryness

$z$ : Axial coordinate, $\mathrm{m}$.

Greek symbols

$\alpha$ : Amplitude of oscillation

$\gamma$ : Specific heat ratio

$v$ : Specific volume, $\mathrm{m}^{3} / \mathrm{kg}$

$\zeta$ : Local resistance coefficient of import

$\rho$ : Density, $\mathrm{kg} / \mathrm{m}^{3}$

$\tau$ : Shear stress, $\mathrm{N} / \mathrm{m}^{2}$.

Subscripts

b: Bubble

c: Capillary

D: Dry filter

g: Gas

l: Liquid

$s$ : Compressor suction pipe

$w$ : Wall.

\section{Data Availability}

All data are available from the corresponding author upon request.

\section{Conflicts of Interest}

The authors declare that they have no conflicts of interest.

\section{Acknowledgments}

This paper was cofunded by the National Natural Science Foundation of China (no. 51776226) and the Postgraduate Independent Exploration and Innovation Project of Central South University (no. ZZTS2020518).

\section{References}

[1] A. R. Mohanty and S. Fatima, "Noise control of a domestic refrigerator using a natural material based composite," Sound and Vibration, vol. 54, no. 4, pp. 247-256, 2020.

[2] Z. Huang, G. Ding, P. Wang, and L. Yao, "Structure design and performance study of serial resistant muffler for refrigerator capillary tube," Fliud Machinery, vol. 45, pp. 80-82, 2017.

[3] D. Bircan, "Flow-induced noise in refrigerators," in InterNoise And Noise - Con Congress, vol. 253, no. 1, pp. 7705-7715, 2016.

[4] H. Koruk, A. Arisoy, and N. Bilgin, "Quantification of the flow noise in household refrigerators," Journal of Vibroengineering, vol. 16, no. 7, pp. 3557-3564, 2014.

[5] K. Langampol, K. Srisomboon, V. Patanavijit, W. Lee, and E. Cuevas, "Smart switching bilateral filter with estimated noise characterization for mixed noise removal," Mathematical Problems in Engineering, vol. 2019, Article ID 5632145, 23 pages, 2019.

[6] R. Anis, E. Amine, C. Wathek, A. Ziyad Ali, and Y. Fu, "An analytic characterization of -white noise functionals," Journal of Mathematics, vol. 2020, Article ID 6319138, 2020.

[7] A. Jawdat, S. Elazab Nasser, M. Mogtaba, R. Anis, E. Ahmed, and H. Ahmad, "Deterministic sudden changes and stochastic fluctuation effects on stability and persistence dynamics of two-predator one-prey model," Journal of Mathematics, vol. 2021, Article ID 6611970, 11 pages, 2021.

[8] R. W. Hofstetter, B. E. Copp, and 1 Lukic, "Acoustic noise of refrigerators promote increased growth rate of the gray mold Botrytis cinerea," Journal of Food Safety, vol. 40, no. 6, Article ID e12856, 2020.

[9] J. Ruebeling and S. Grohmann, "Flow-induced noise generation at the outlet of a capillary tube," International Journal of Refrigeration, vol. 111, pp. 188-196, 2020.

[10] M. S. Kim, W. B. Jeong, and H. S. Han, "Development of noise pattern map for predicting refrigerant-induced noise in refrigerators," Journal of Mechanical Science and Technology, vol. 28, no. 9, pp. 3499-3510, 2014

[11] H. S. Han, W. B. Jeong, and M. S. Kim, "Frequency characteristics of the noise of R600a refrigerant flowing in a pipe with intermittent flow pattern," International Journal of Refrigeration, vol. 34, no. 6, pp. 1497-1506, 2011.

[12] H. S. Han, W. B. Jeong, M. S. Kim, and T. H. Kim, "Analysis of the root causes of refrigerant-induced noise in refrigerators," Journal of Mechanical Science and Technology, vol. 23, no. 12, pp. 3245-3256, 2009.

[13] M. S. Kim and W. B. Jeong, "Analysis of the cause and reduction of refrigerant-induced noise in refrigerator," Journal of Mechanical Science and Technology, vol. 2010, no. 5, pp. 5572-5578, 2010.

[14] Y. Xia, Y. Liu, Y. Liu, Y. Ma, C. Xiao, and T. Wu, "Experimental study on reducing the noise of horizontal household 
freezers," Applied Thermal Engineering, vol. 68, no. 1-2, pp. 107-114, 2014.

[15] M. Strasberg, "Gas bubbles as sources of sound in liquids," The Journal of the Acoustical Society of America, vol. 28, no. 1, pp. 20-26, 1956.

[16] M. Minnaert, "On musical air-bubbles and the sounds of running water," The London, Edinburgh, and Dublin Philosophical Magazine and Journal of Science, vol. 16, no. 104, pp. 235-248, 1933.

[17] H. S. Han, W. B. Jeong, M. S. Kim, S. Y. Lee, and M. Y. Seo, Reduction of the refrigerant-induced noise from the evaporator-inlet pipe in a refrigerator," International Journal of Refrigeration, vol. 33, no. 7, pp. 1478-1488, 2010.

[18] M. B. Pate, "A theoretical and experimental analysis of capillary tube suction line heat exchangers," Ph.D. thesis, Purdue University, West Lafayette, IN, USA, 1982. 